\title{
Improving Writing Through The Peer-To-Peer Evaluation Process
}

\author{
Donald A. Forrer, Hodges University, USA \\ Nancey A. Wyant, Hodges University, USA \\ Minnette G. Smith, Hodges University, USA
}

\begin{abstract}
This presentation will demonstrate the process utilized in graduate and undergraduate level classes at Hodges University to improve writing skills through a Peer-to-Peer evaluation. The research addresses the utilization of a rubric where students evaluate a minimum of two fellow classmates and share their critique in an online discussion board. Students evaluate classmates on assignment coverage, critical thinking, conceptual fluency, writing fluency, and information literacy. The rubric provides specific sub-categories that guide students as they evaluate classmates. Once the student evaluation process is complete, student research is critiqued by the professor prior to submission of the research paper. This presentation will cover usage of the rubric and statistical results from initial testing. Innovative professors must continue to enhance the quality of their online delivery in an effort to achieve the same educational outcomes acquired in a traditional classroom. While this process works very well in a traditional classroom setting, this presentation demonstrates how the same process can be utilized effectively in an online environment.
\end{abstract}

Keywords: Faculty; Assessment; Innovation; Technology; Inductive Learning; Online Environment; Online Faculty; Pedagogy

\section{INTRODUCTION}

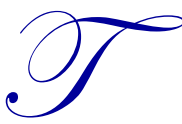

his research is centered on the concept that students learn best when challenged and provided quality feedback prior to the submission of a project for grading. Additionally, the more a student understands an assignment, the better the end result. The peer-to-peer review process is not a new concept, but it is not widely utilized for various reasons. The premise of this research is that students participating in a well-defined peer-to-peer review process perform better than students submitting research with little or no review process. This paper analyzes the use of a peer-to-peer review process in four online courses at Hodges University. Results will be utilized to enhance the educational process and for future research.

In today's educational system it is important that professors utilize inductive learning and innovation to ensure that a student graduates with the writing and research skills necessary to be successful in his/her field. Professors cannot rely on traditional classroom techniques such as utilizing lectures, models, theory, and examinations. These methods must be augmented by innovative inductive learning techniques such as a peer-topeer review process.

A continuous challenge for faculty is to engage students in inductive learning techniques that will facilitate improved learning. Active learning is an approach identified by Chickering (1987) as a method to involve students in critical thinking exercises. Active learning was an early attempt to involve students inductively by making them responsible for the quality of their peers as well as their own assignments. While active learning involved more than peer review assessments, this research will concentrate on the peer aspects of assessment and evaluation.

The peer review process requires change in an educational system that is sometimes reluctant to change. This research concentrates on the art of online learning. Inductive learning is critical to the success of an online 
environment and this is a change that must occur or the institution will only deliver glorified correspondence courses. According to Orlikowski and Hofman (1997), organizations change as they perceive the need. This is usually demanded by accreditation standards, but should be part of the innovation initiatives of the institution. This research will make the point that inductive learning should be part of the marketing model to attract students who want to use knowledge gained in the class room for professional purposes.

\section{Conceptual Framework}

Teaching and learning in higher education is dependent upon effective assessment. Students must be afforded a well-designed assessment instrument where the expectations are thoroughly outlined, students have an opportunity to practice, and feedback is effective. The faculty member must be involved at every level. The use a of peer-to-peer review process to create an inductive learning activity provides students with all three criteria and an opportunity to view the big picture by observing how others approached the assignment.

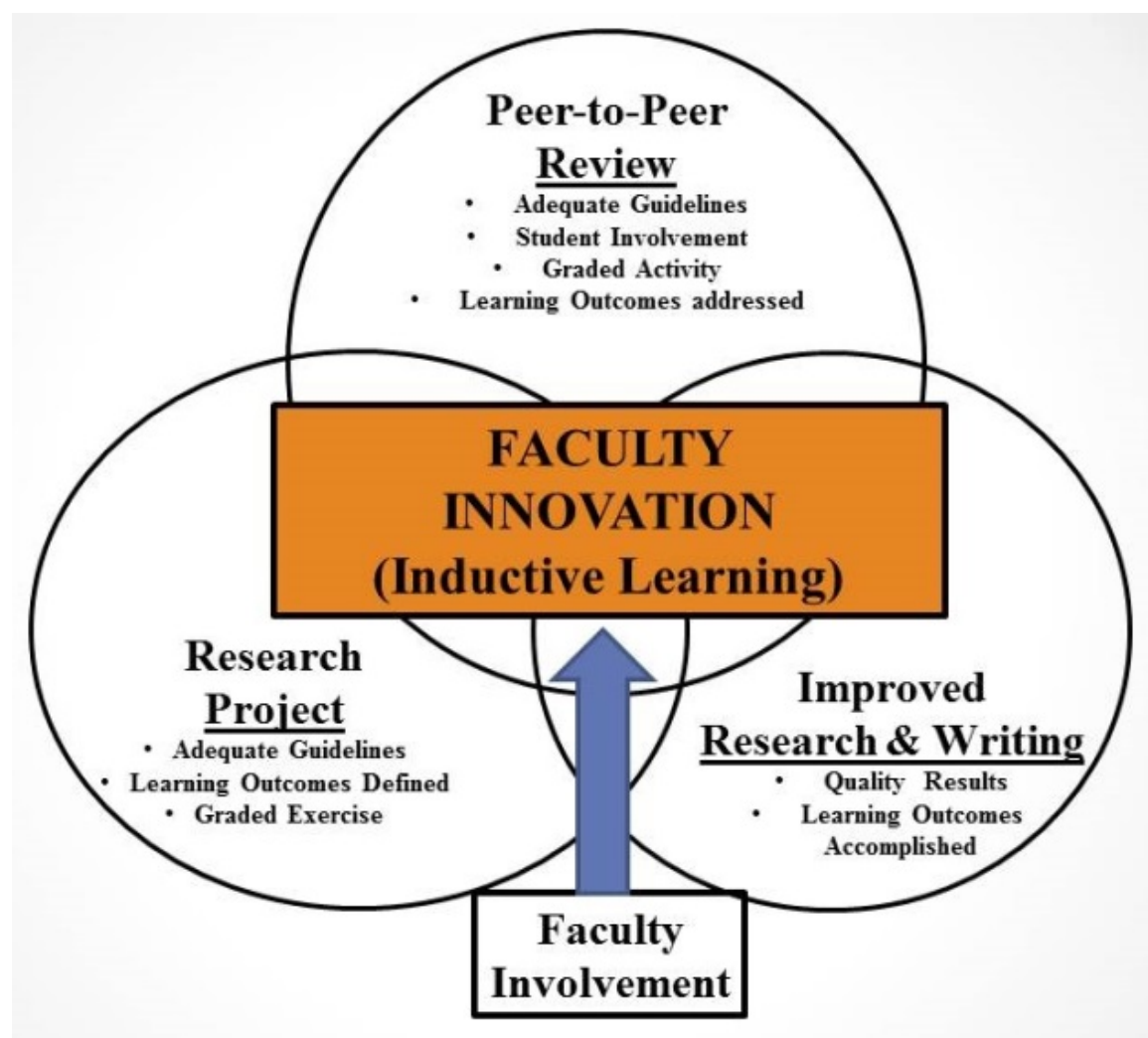

Figure 1. Conceptual Framework. Created by authors.

The conceptual framework in figure 1 demonstrates how this study was designed. A research project measuring learning outcomes for the course was developed for five online courses. Guidelines were established and the exercise contributed significantly to the final grade for the course.

\section{PEER-TO-PEER REVIEW}

For the purpose of this research, peer review is defined as getting students involved in the evaluation of fellow classmate's research (van den Berg, Admiraal, \& Pilot, 2006). Research indicates that peer involvement in the evaluation of others is an effective method of developing cognitive skills. Students identify strengths and weaknesses along with the ability to work toward specific learning outcomes. The process of evaluation becomes a learning tool that develops critical thinking and improves the student evaluator's work as well as the individual assessed (Prins et. al., 2005). 
This research is designed to determine if peer-to-peer evaluation by itself is a contributing factor to improved research and writing in an end-of-term research project. Additionally, this research will determine if students apply critiques by fellow classmates to the final paper submitted. The hypothesis for this research is:

H1: The peer-to-peer research process will significantly increase research results from the first draft to the final submission of an end-of-term research project.

This study included four (4) graduate level and one (1) senior level undergraduate courses at Hodges University. While course topics were different, instructions for the research projects were consistent. Each course followed the same peer-to-peer review processes.

The peer-to-peer process utilized in this research is an inductive learning technique designed to involve students in the grading process in a way that requires critical thinking and honesty on the part of the student evaluator. Inductive learning as defined by Prince and Fielder in 2007 is "Instruction that begins with a challenge for which the required knowledge has not been previously provided technically qualifies as inquiry-based learning, and the scope of the inquiry may vary from a portion of a single lecture to a major term project. In this sense, all inductive methods are variants of inquiry, differing essentially in the nature of the challenge and the type and degree of support provided by the instructor"(p.15).

Inductive learning techniques better prepares students for real-world situations than traditional methods such as lectures and examinations. The peer-to-peer review involves students in an inductive manners much like other examples such as case-based learning, problem- based learning, discovery learning, and just-in-time teaching. Working with students to solve a real-world situations problem help develop the skills required to become subject matter experts. Critically reviewing fellow classmate's projects will improve student's research techniques.

\section{LITERATURE REVIEW}

The peer-to-peer review process can be mandated by the university or an innovative process utilized by the professor to improve research and writing. Research by Orlikowski (2000) determined that, when measuring innovation, organizational structure was not a physical entity, but institutional knowledge activated by action on the part of staff and faculty. Therefore, educational institutions are an open-ended change model that measures innovation among faculty by how they collectively respond as conditions change. Academia is currently addressing research and writing due to problems surfacing throughout the nation. The elevated usage of inductive learning is a strong tool for improving this condition.

The strategy of using peer evaluation is important because students are required to assume an active role in the learning process (Lui \& Carless, 2006). In other words, peer review is a strategy where students are selfregulated and forced to make judgments about fellow learners based on criteria determined by the professor, the learning objectives, and the course materials. Students cannot rely on their strong desire to be kind to friends, but must be critical if required to earn the desired learning outcome and, more importantly, grade. It must be noted that the research conducted by Lui \& Carless suggested that using grades in the peer review hinders the process from influencing learning outcomes in a positive manner.

According to Odom et al., (2009), peer review is a valuable strategy that causes students to think collaboratively, evaluate scholarly research, and to use evaluation skills. The research conducted by Odom et al., suggests that students benefit regardless of the outcome of the evaluation due to the experience. Basheti et at., (2010) determined that peer assessment enables students to understand clearly how to achieve learning outcomes and makes them responsible for their learning. According to research by Basheti et al., benefits from peer assessment included comparison of approaches and standards plus information exchange among peers. This research used anonymity in the process and $95 \%$ of the participants indicated this was helpful. This supports findings by Lui \& Carless, (2006) that grades could be a hindrance in the peer review process.

Current research is divided among scholars as to the effectiveness of peer-to-peer assessment. According to Sivan (2000), peer assessment is a valuable tool to create self-motivated learners. This research believed that the 
peer process developed students into critical thinkers by allowing them to evaluate peer performance and apply results to their own work. Students learned from mistakes and creativity through the peer process. The peer review process can also help professors by providing additional feedback to improve research and writing skills. The caveat to this is that professors must be heavily involved or students may receive erroneous feedback.

The peer review process provides an opportunity for students to be cognitively involved by reviewing and correcting fellow classmates work. The process provides new knowledge to assessors by exposing them to the research and opinions of others (Ballantyne et al., 2002). This research found that students work to discover key points in research through an evaluation of their peers. The process made students more self-reliant rather than waiting on feedback from an instructor. A study by Thompson et al, 2005 found that peer review made students focus on quality, evaluate and reflect on their own work, and think critically. However, this study indicated that success was highly dependent on how the peer assessment was communicated and the grading rubric associated with the evaluation. Again, faculty involvement was a key to success.

Feedback is a proven method of improving student performance. The more feedback received by students, the better the product quality. Collaborative work among peers is valuable as it provides an opportunity to experience real-world activities. The process of providing critical feedback in a group setting is common and required in a corporate setting. Reece-Durham (2005) highlighted faculty involvement by demonstrating how students perform better when assessment instruments are shared with them to ensure that they understand how to utilize them. Reece-Durham's study indicated that a student's understanding of the evaluation criteria would result in clear learning objectives, interdependence among students, positive attitudes, and accountability.

Peer review is widely utilized in industry in fields such as information technology. Practioneers in this field utilize peer review techniques to find errors before the product is sent to market. This is commonly called beta testing and can be implemented through several methodologies, but always involves peer review (Norton and Schulman, 2010). Software engineering, code inspection, and software development are among the many uses for peer evaluation in industry. Using peer evaluation to improve research and writing will improve a student's chances of becoming successful after graduation.

A study by Brammer and Rees (2007) reviewed peer evaluation from the student's perspective. Their research found that very few empirical studies concentrated on how the student felt about peer assessments. They found that students were usually skeptical and concerned about quality, effects, and methodology. Brammer and Rees found a level of distrust among students that peers could be trusted in the absence of detailed faculty involvement. Student's in the study required a high level of communication and were at times unwilling to be critical of fellow classmates.

\section{ANALYSIS}

In this research, students are required to submit a draft research paper to the discussion board in week ten of a fifteen week semester. Students are then assigned two fellow classmates to analyze using a grading rubric that evaluates several key elements in the following topics; 1) introduction and topic identification, 3) information use and literature review, 2) critical thinking and analysis of information, 4) information use and writing fluency, and 5) obtaining information, legal, ethical, and APA. The key elements represent quality criteria for evaluation in each area.

The list of quality criteria for the student Peer-to-Peer rubric includes: 1) Introduction \& Topic Identification, 2) Information Use \& Literature Review, 3) Critical Thinking \& Analyze Information, 4) Information Use \& Writing Fluency, and 5) Obtain Information, Legal, Ethical, and APA. In addition to the elements examined, the rubric requested specific comments and a point value recorded in a Likert scale of; excellent, acceptable, weak, or unacceptable. This challenged the integrity of each student to be honest with a peer in the process of evaluation. The peer-to-peer review process was designed and communicated to students. Students deposited a draft paper in the discussion board and the paper was reviewed by two fellow classmates utilizing the peer-to-peer rubric and instructions from the instructor. 
The draft paper was also evaluated by the professor utilizing the peer-to-peer faculty rubric. The faculty peer-to-peer rubric is a modified version of the Hodges University Research ability rubric that included much of the same verbiage as the peer-to-peer rubric. Students were provided one week to review fellow classmates work and then all peer reviews were posted for the entire class to read. Students were then provided one week to submit final papers with peer corrections applied. The faculty evaluation of the draft submission was not shared with students, but used as a comparison to determine improvement. This study will determine if improved research and writing skills resulted from the peer review. Faculty involvement included providing guidelines, guidance, and consultation to ensure learning objectives were addressed.

\section{Data Collection}

As noted earlier, students were required to deposit their draft research paper in the discussion board by week ten (10). Students then utilized the next two weeks to evaluate fellow classmates using the peer-to-peer grading rubric. Rubrics were deposited in the discussion board by the end of week twelve (12). At this point, each student utilized the two peer evaluations to make changes as required. The completed research paper was then submitted to the professor by the end of week thirteen (13). Students received feedback by the end of week fifteen (15).

Additionally, as part of the process, draft research papers submitted in week ten (10) were evaluated by the professor utilizing the Hodges University research ability grading rubric. The results were noted and compared to the final research submission in week thirteen (13). This process measured the effectiveness of the inductive learning exercise. The table below lists results of a basic statistical analysis. It was determined that the study needed to be strengthened and new data collected prior to a more in-depth statistical analysis. However, the data in table 1 provides valuable insight.

Table 1. Data Analysis

\begin{tabular}{|c|c|c|c|c|c|c|c|c|c|c|c|c|}
\hline \multirow[b]{2}{*}{ Variables } & \multicolumn{3}{|c|}{ Combined Data } & \multicolumn{2}{|c|}{ Peer-to-Peer } & \multicolumn{2}{|c|}{ Prof (Draft) } & \multicolumn{2}{|c|}{ Prof (Final) } & \multicolumn{3}{|c|}{$\begin{array}{c}\text { Peer/Draft } \\
\text { compared to Final }\end{array}$} \\
\hline & $\mathbf{N}$ & F-value & R-SQ & Mean & S.D & Mean & S.D & Mean & S.D & Source & t-Value & Sig \\
\hline \multirow[t]{2}{*}{ Intro } & 34 & 18.007 & .530 & 2.87 & .67933 & 2.65 & .67933 & 3.34 & .59125 & Peer & -.363 & .719 \\
\hline & & & & & & & & & & Draft & 1.376 & .182 \\
\hline \multirow[t]{2}{*}{ Lit Rev } & 34 & 11.930 & .427 & 2.87 & .67933 & 2.74 & .67933 & 3.17 & .70651 & Peer & 1.790 & .086 \\
\hline & & & & & & & & & & Draft & 2.030 & .054 \\
\hline \multirow[t]{2}{*}{ Analysis } & 34 & 12.205 & .433 & 2.88 & .57843 & 2.85 & .57943 & 3.14 & .60112 & Peer & .909 & .373 \\
\hline & & & & & & & & & & Draft & 1.168 & .254 \\
\hline \multirow[t]{2}{*}{ Writing } & 34 & 8.856 & .356 & 2.81 & .66579 & 2.71 & .66579 & 2.94 & .48149 & Peer & -.896 & .379 \\
\hline & & & & & & & & & & Draft & .973 & .340 \\
\hline \multirow[t]{2}{*}{ APA } & 34 & 13.649 & .460 & 2.62 & .76464 & 2.77 & .76464 & 3.34 & .72529 & Peer & 01.507 & .145 \\
\hline & & & & & & & & & & Draft & 2.986 & .006 \\
\hline Grade & 34 & 9.983 & .806 & & & & & 90.51 & 5.54326 & Final & 11.294 & .000 \\
\hline
\end{tabular}

The initial hypothesis for this research was that the peer-to-peer review process will significantly increase the quality of the final project. Initial data indicates that there was improvement between the peer review and final submission. However, the differences were not as significant as expected. Data and observation indicates that students did not use peer critiques to improve the final product in the manner anticipated. Two elements of the study - writing and analysis - showed only slight improvement. This was also true in regards to the literature review. The two elements demonstrating significant improvement were the introduction and APA usage. Observations by the primary grader indicate that students made very few changes based on the peer-to-peer review process. Data in table 1 supports this conclusion.

The results of this study proved valuable for several reasons. This is the first of a series of studies in an effort to perfect the process and the grading rubics. During this study, students were left on their own to apply comments from the peer rubric. For the next study, students will be required to submit an approved peer-to-peer rubric with an explanation of how they used comments from fellow classmates. This improved rubric will be a required addition to the final research project. 
During this study, a faculty evaluation was conducted and utilized for comparison between the draft submission and the final project. This evaluation was not provided to students as it served as a basis for judging improvement. This procedure will not change for the next study as this research is focused on the peer as a primary source of improvement.

As noted earlier, the statistical data is only a cursory review as future studies will utilize improved rubrics and procedures and warrant a closer analytical effort. The data collected indicate that the study was valid and showed progress based on the peer review. Future studies will strengthen procedures and provide a statistically valid result.

\section{CONCLUSION}

This research served to highlight areas needing improvement in the peer to peer review process. Instructions to students must be improved and the process changed to require a response to whether or not comments were utilized to improve the final product. Students must be involved at an earlier stage in the process to ensure they understand requirements and processes.

One limitation to this research is that results of the draft peer-to-peer faculty rubric were not shared with students. This was by design as a follow-up study is scheduled to include faculty feedback in conjunction with peerto-peer feedback. Another limitation included the fact that students were not required to respond to fellow classmates as indicated on the peer-to-peer rubric. This process will also be part of the Fall-2014 study.

This current study was designed to determine how peer-to-peer feedback effected research and writing in the course research project. The next study will add a graded exercise where students must explain how they utilized peer feedback in their final paper. The draft evaluation by faculty will still remain hidden from students to ensure a basis for comparison.

\section{AUTHOR INFORMATION}

Don Forrer has a Doctorate in Business Administration and serves as a Professor in the MBA/MPA program at Hodges University (formerly International College) of Naples, Florida. Additionally, Don is the CEO/President of Cybernetics Concepts, a management consulting team specializing in utility economics. He served as a management professor at Troy University, Strayer University, Embry-Riddle University, Central Michigan University \& International College. He has lectured on management topics in Taiwan, Japan, Guam, and throughout the United States.

Dr. Nancey A. Wyant is the Dean of the Johnson School of Business at Hodges University in Naples Florida.

Minnette G. Smith is English faculty and the director for the Writing in the Disciplines QEP at Hodges University. Prior to working for Hodges University, she was the Managing Editor at Wheaton College. Minnette has her Master's Degree in Rhetoric and Composition from The University of South Florida.

\section{REFERENCES}

Ballantyne, R., Hughes, K., and Mylonas, A. (2002). Developing procedures for implementing peer assessment in large classes using an action research process. Assessments and Evaluations in Higher Education, 27(5), 427-441.

Brammer, C., and Rees, M. (2007). Peer review from a student's perspective: invaluable or invalid? Composition Studies, 35(2), 71-85.

Basheti, I., Ryan, G., Woulfe, J., \& Bartimote-Aufflick, K., (2010). Anonymous peer assessment and medication management reviews. American Journal of Pharmaceutical Education, 74(5). Article 77.

Chickering, A. W., (1987). Seven principles for good practice in undergraduate education. AAHE Bulletin, 2-6.

Liu, N., \& Carless, D., (2006, July). Peer feedback: the learning element of peer assessment. Teaching in Higher Education, 11(3), 279-290. 
Norton, D. and Schulman, J. (2010). Seven best practices for your agile software factory. Garner Research 10. DOI: G00173140.

Odom, Sue., Glenn, Betty., Sanner, Susan., \& Cannella, Kathleen A.S., (2009). Group peer review as an active learning strategy in a research course. International Journal of Teaching and Learning in Higher Education, 21,108-117.

Orlikowski, W. \& Hofman, J. (1997). An improvisational model of change management: the case of groupware technologies. Sloan Management Review, 38(2), 11-21.

Orlikowski, W. (2000). Using technology and constituting structures: A practice lens for studying technology in organizations. Organizational Science, 11, 404-428.

Prince, M., \& Felder, R. (2007, March/April). The many faces of inductive teaching and learning. Journal of College Science Teaching, 36(5). 14-20. Retrieved from http://mate.calpoly.edu/media/files/Prince Felder.pdf.

Prins, F.J., Sluijsmans, D., Kirschner, P., \& Strijos, J. (2005). Formative peer assessment in a CSCL environment: A case study. Assessment \& Evaluation in Higher Education, 40(4), 417-444.

Reece-Durham, N. (2005). Peer evaluation as an active learning strategy. Journal of Instructional Psychology, $32(4), 338-348$.

Sivan, A. (2000). The implementation of peer assessment: an action research approach. Assessment in Education, 7(2), 193-213.

Thompson, G., Pilgrim, A., and Oliver, K. (2005). Self-assessment and reflective learning for first year geography students: a simple guide or simply misguided? Journal of Geography in Higher Education, 29(3), 403-420.

Van den Berg, I., Admiraal, W., \& Pilot, A. (2006). Design principles and outcomes of peer assessment in higher education. Studies in Higher Education, 31(3), 341-356. 


\section{NOTES}

